\title{
AR Module for Learning Changes of Matter in Chemistry
}

\author{
https://doi.org/10.3991/ijim.v15i23.27343
}

\author{
Mangai Solomon Mahanan ${ }^{1(\bowtie)}$, Nor Hasniza Ibrahim ${ }^{1}$, Johari Surif ${ }^{1}$, Chee Ken Nee \\ ${ }^{1}$ Universiti Teknologi Malaysia, Johor, Malaysia \\ ${ }^{2}$ Universiti Pendidikan Sultan Idris, Perak, Malaysia \\ solomonmangai2018@gmail.com
}

\begin{abstract}
Internal Visualization challenges concerning sub-microscopic particles in chemistry often result in some difficulties in learning the change of state of matter. Therefore, this study aims at developing an augmented reality ProCAR module that utilizes a project-based learning approach to facilitate learning changes of matter. This study employs ADDIE (Analysis, Design, Development, Implementation and Evaluation) instructional design model. The quality of the module was evaluated by a group of 5 Chemistry teacher-educator experts of Universiti Teknologi Malaysia to identify the suitability of the module. Inter-rater reliability (IRR) percentages were determined and the feedback was analyzed based on thematic analysis. The result shows that $100 \%$ of its learning objectives, Content, Usability, and Assessment and $75 \%$ of its performances were good and reliable all having IRR value $75 \%$ and above. Such revealed that AR Module is potentially effective for the teaching of phase change to Secondary school students. Recommendations for future studies were highlighted.
\end{abstract}

Keywords - AR module, project-based learning, augmented reality, phase change, STEM

\section{$1 \quad$ Introduction}

Chemistry education is a learning area that researchers have explored by experimenting with various teaching aids to enhance better learning of chemical concepts at the secondary school level. For example, modules by [56], [37], [38] have been developed to improve better teaching and learning of chemistry. Chemistry is a science subject that is a component of Science Technology Engineering and Mathematics (STEM) has received different perceptions by students on the learning difficulty due to several factors associated with the visualization of chemical phenomena [34]. The difficulty involves learners' inability to create a mental picture of chemical entities and processes at the sub-microscopic level [12], [31], [32].

\subsection{Students' difficulties in mastering the topic of changes in matter conditions}

Hence, there is often a case of low academic achievement in STEM due to poor attitude risen from this difficulty that comes with many factors such as the pedagogy which 
is sometimes a traditional approach employed in giving instruction [24]. This only gives little description of the concepts without explicating the depth of the content to be learned. The ability of students to visualize chemical phenomena can contribute to students' understanding thereby improving their knowledge of chemistry [4]. According to [22], enhancing visualization of chemical phenomena is adequate for our students as they may find it very easy to integrate the chemical knowledge into STEM. Therefore, Augmented reality is a digital 3D technology that is recently applied in education to enhance the learning of chemistry concepts. The technology helps in promoting the learning of sub-microscopic particulate content of chemistry which is not easily visualized without the aid of a model.

\subsection{Effective teaching and learning strategies to address student difficulties}

States of the matter is a topic in chemistry whereby learners require depth knowledge of the particulate nature of matter to understand the actual processes that take place at the sub-microscopic level. Therefore, augmented reality is especially critical in aiding the understanding of these sub-microscopic chemical entities through augmenting the sub-microscopic reality. The learning of States of Matter can be meaningful if learners are engaged in STEM activity that allows them to relate the conceptual knowledge with the real-life experience. This is can be achieved through a Project-Based Learning strategy that can allow learners to utilize an Augmented reality device to visualize the molecules as they undergo a phase change from liquid to solid-state.

Augmented reality. Augmented reality is a technology that integrates computergenerated virtual reality with the real world and allows the user to sense the natural environment with the virtual experience [21]. Technology has received tremendous applications in education. [19], claim that augmented reality has the potential to motivate and improve learning. The reception experienced of augmented reality and interest shown in implementing the technology in education seems promising towards enhancing the students' learning. According to [30], students' achievements were observed to increase after giving instructions with augmented reality. This technology consists of a wide range of benefits for learning which encompasses accommodation of students of various school levels, involvement of students' participation as they interact with real-world and virtual observation [30].

Project-based learning. Project-Based Learning is a learning strategy that demands students to actively engage in learning processes or activities within a real context that will lead them to develop a specific project by solving the problems associated with developing this project (Kokotsaki et al., 2016; [29]. The emphasis here is not only placed on the outcome of the project but also on the expected and unexpected learning outcomes that result from the process of engaging through the project. It is often carried out in groups which offers a collaborative learning opportunity amongst the students. When students are granted autonomy in this learning strategy, there is much likelihood that their performance will increase [9].

STEM. STEM is a learning approach that integrates knowledge and principles of science, technology, engineering and mathematics [18]. This approach provides a unifying knowledge that is not restricted to specific subjects [28]. Students learning 
through STEM approach can be inculcated with critical thinking ability and effective problem-solving skills that can be beneficial for those seeking for advanced studies within STEM higher education or STEM-related occupations [5]. [30], [6] described STEM as a "pedagogical applications based on design and engineering technology for teaching content and practice in science and mathematics education" p. 645. The need to engage a student-driven learning where learners can implement knowledge of content into real-life practices is critical to STEM learning approach [31], [16]. This can help towards realization of the $21^{\text {st }}$ century aspirations [32], [27], [28]. Overall, all the potential strategies in helping students understand the topic of changes of matter in more depth can be implemented by developing a learning module that can facilitate their learning through engaging in STEM learning activity. According to [27] STEM learning modules are very helpful for teachers in producing a teaching and learning process that not only improves students' understanding but also can help students apply it in daily life.

\section{Study aim}

This study aims to develop an AR module that will facilitate understanding of phase change through students' active participation in STEM projects. The project activity in this paper is the preparation of homemade ice cream with the aid of the AR module.

\section{Methodology}

This study utilized a descriptive design by using ADDIE instructional design. The design provides five phases to help in the development of the AR module which includes Analysis; Design; Development; Implementation; and Evaluations. The ADDIE model is commonly used by many instructional designers to develop instruc-tional systems [26]. A group of 5 chemistry teacher-educator experts who are lecturers in Universti Teknologi Malaysia were sampled for the study through a purposive sampling technique. The criteria for selection include at least 5 years working experience both at the university and secondary school level teaching chemistry and how it should be taught, familiarity with students' difficulties in learning phase change, specializes in Project-based Learning in STEM and understanding the advantages and disadvantages of augmented reality. The instrument (an open-ended questionnaire) administration and data collection were done through google form. Data obtained at $100 \%$ response rate was then sorted according to codes, themes and sub-themes through a thematic analysis [34], [17]. In each theme and subthemes, the percent-age inter-rater reliability (IRR) which determines the extent of agreement amongst two or more evaluators (raters) was determined [33], [14]. A result from these analyses was presented and discussed.

\section{$4 \quad$ AR module development}

The development of the AR module was done through the following phases. 


\subsection{Analysis phase}

The initial stage of the instructional design ADDIE model is the Analysis stage. This stage provides a need analysis in regards to the problem facing effective teaching and learning. According to [12, p. 228] "needs analysis is conducted to determine the needs of the audience by distinguishing between what students already know and what they need to know at the conclusion of the course". The stage basically, provides information on the factors that leads to students' unsatisfactory performance which presents a problem to instructors which calls for a solution [13]. [8, p. 82], described this analysis stage as "identifying the probable causes for a performance gap.

From previous works of literature students have been found to portray little understanding of phenomena related to size and number of particles during change of state of matter. For instance, a study by $[25$, p.12] showed that "a majority of the students in all grades think that the size and number of particles will change during phase changes". Similarly, students believed that during phase change magnitude of particles changes both quantitatively and qualitatively [33]. This notion might lead to difficulty developing mechanistic reasoning about the actual chemical reactions that take place in topics dealing with chemical and physical changes. Furthermore, a study by [1], described that majority of students before its study intervention held the notion that no vacuum exists between particles in the three states of matter. Some students also described that all solid substances have a fixed shape that does not change and an object like a sponge is not a solid [23]. That is to say, students encounter difficulty largely due to the abstractness of the microscopic reality which becomes difficult for them to visualize. More so, in current practice, the response from the chemistry teachers interviewed was in line with the outcome from the literatures identified in which most students have difficulty demonstrating the actual sub-microscopic reality related to size, as well as the number of molecules during phase change, say from liquid to solid and vice versa.

\subsection{Design phase}

This phase is another critical stage of the module development process whereby planning and research are done simultaneously. Based on the outlined propositions of the design phase, the learning objectives that should be achieved in this study are enumerated as follows:

a. Develop appropriate descriptive knowledge of the concepts of phase change.

b. Conceptualize the appropriate linkage between sub-microscopic reality, macroscopic and symbolic representations.

c. Apply the Knowledge of phase change in real life.

d. Communicate by presenting their knowledge about the concepts learned, their existence, and their application in real life.

Having outlined the learning objectives, the next is to determine the instructional strategy that would be employed in achieving the learning objectives. All the processes are monitored and guided by the teacher where necessary. Never at all does the teacher provides a guideline to be followed on how to carry out each activity [29]. 
Table 1. Example of AR module lesson plan

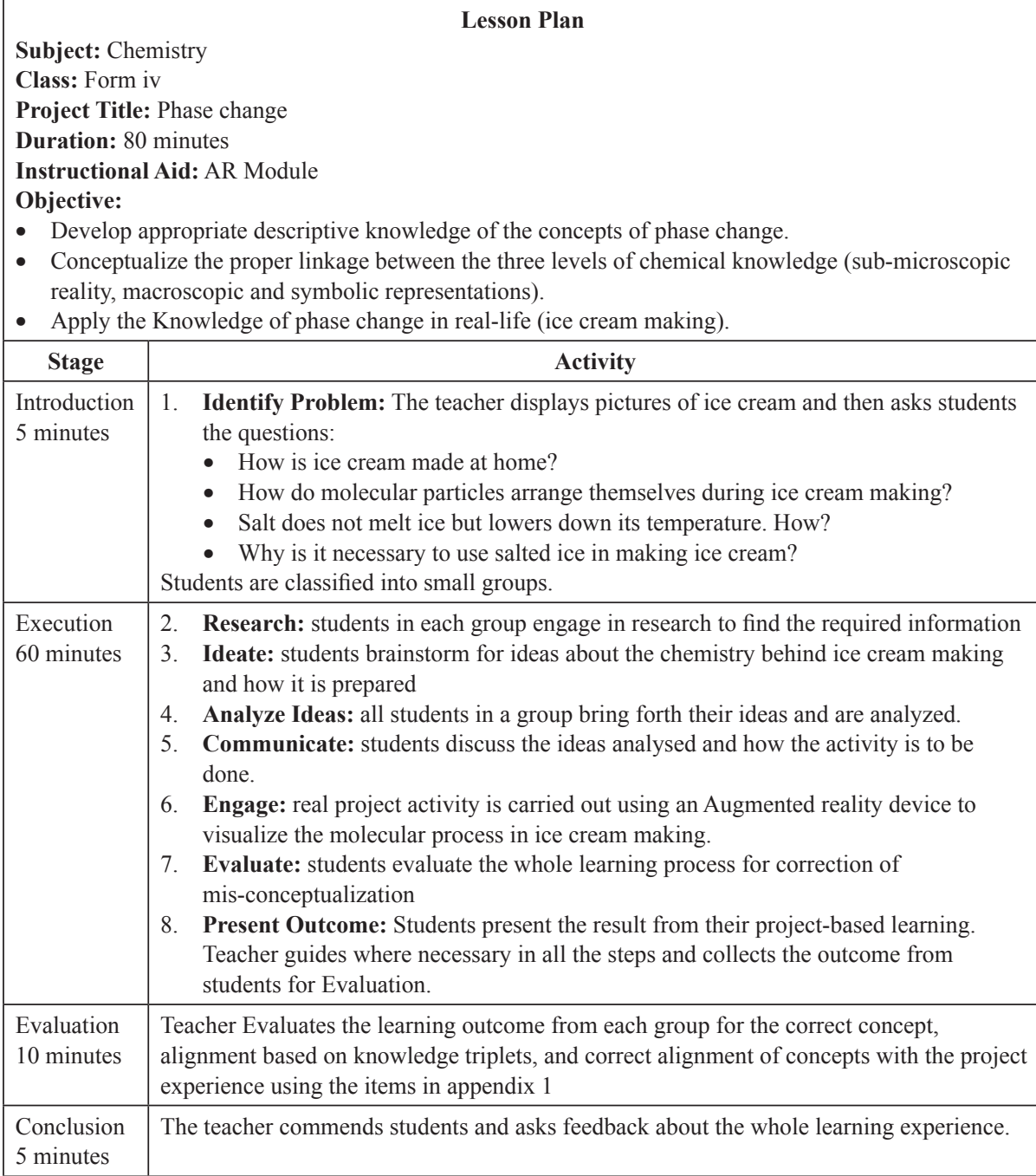

The lesson plan comprises of four main stages (introduction, Execution, Evaluation and Conclusion). Introduction is the first stage where the problems are identified through asking questions. The teacher asks the students a set of provocative questions that can arose their curiosity for wanting to learn. At the second stage students make research, develop the idea, analyse ideas obtained, discuss, put the plan to effect, evaluate activities, and present the outcome to the teacher. At the third stage the teacher assesses the students' outcome and the feedback is given to students. Last stage is where students are commended and asked for feedback on the interesting and challenging aspect during the learning experience. 


\subsection{Development phase}

This phase constitutes building up the AR module content by following the guideline outlined in the analysis and design phase.

The AR module content. The module comprises three sections:

\section{a. Introduction of AR module}

i) Description of Phase Change concept

ii) Description of Project-based learning

iii) Description of Augmented reality

iv) Description of STEM

Development of AR system. The AR system was developed based on the learning activity contained in the AR module. It contains features that can enable the users to navigate through the steps. Its unique feature is that it provides description of temperature at which the physical change is taking place and the choices for which flavour to be used in the ice cream making. Figures 1 and 2 shows few displays of the AR.

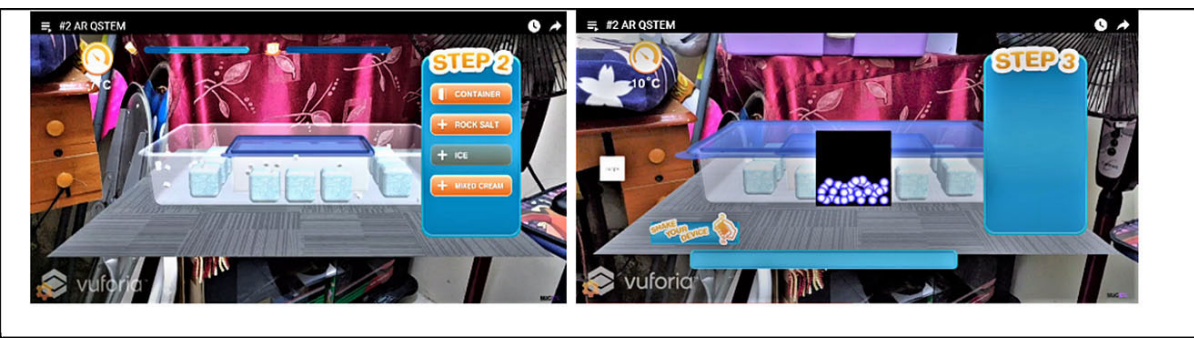

Fig. 1. Augmented reality view of step 2 and 3 of ice homemade cream making

The AR system comprises steps 1-4. Each step comprises of several displays which students can operationalize to observe the ontology of physical changes from liquid ice cream mixture to the solid form. Step 3 of Figure 1 shows how the liquid ice cream molecules move about randomly when the AR device is shaken. The internal heat of liquid ice cream molecules is lost to the cold salted ice-crystals in the larger container surrounding the smaller container that holds the ice cream mixture. Gradually, the molecules become compacted into a solid state when the expected ice-cream is formed as shown in Figure 2. 

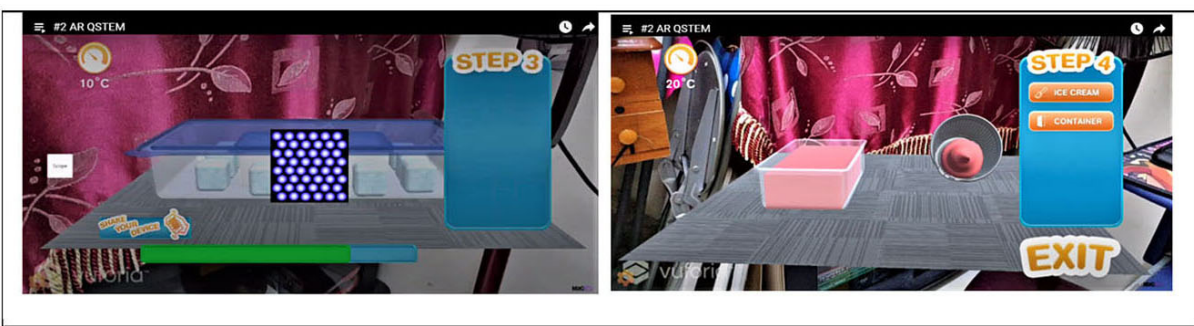

Fig. 2. AR view of solid ice cream

\section{b. Implementation}

The second part of the AR module is the implementation stage. Students with the guidance of the teacher engage in learning the concept of phase change by preparing homemade ice cream. The concept of phase change as regards home-made ice cream is considered based on four areas:

a. Size of particles

b. Number of particles

c. Distance between particles

d. Arrangement of particles

e. freezing point depression effect of salt on ice.

An Augmented reality device is used to visualize the particles as the liquid ice-cream mixture turns into solid ice cream. A lesson plan is used as a guide during the learning process.

\section{$5 \quad$ Results/discussion}

Result of the study is presented based on the 5 main themes and 29 sub-themes.

\subsection{Teaching objectives}

Teaching objectives give direction to what need to be learnt at by the end of a lesson. Therefore, the AR Module's teaching objectives were evaluated and the result shows that 3 subthemes: Clear objectives; Objectives-teaching activities and strategies alignment, and Objectives can achieve learning outcome, were agreed amongst the evaluators which consequently resulted in $100 \%$ IRR value. Only the "objectives-module goals achievement" subtheme had less IRR value of $80 \%$.

The result from the evaluators suggests that there is no ambiguity in the declaration of purpose. Stating clear objectives is important in developing a suitable module. [40] highlighted instructional objectives as crucial to instructional planning which are normally directed towards effecting certain changes in a leaner. According to [41] objectives describes the performances that teacher wish students to demonstrate when the 
learning takes place. Normally, these objectives offer concise expectation to what sort of knowledge or skills about the chosen topic should be achieved by students [39]. Therefore, the AR module comprised not only the module and teaching objectives to fulfil the requirement of a standard instructional plan or material, but having it presented in clear terms is significant in making sure the teacher using the module understands the purpose of the module. Another aspect regarding the objective of the module is having appropriate alignment between objectives and intended learning outcomes, objectives and module goals, and objectives and assessment. This is because the teacher using this module can be confident that students will most likely achieve the learning objectives after the learning process is completed.

\subsection{AR module's content}

The content of the module is critical as it provides the necessary information and strategy required for students to construct their knowledge. From the experts' evaluation, Table 2 shows that 5 subthemes which include: Content complies with learning Objectives; Content aligns with Ministry of Education (MOE) Chemistry curriculum, Activity corresponds with the content of module; Arrangement of module's content is logical and coherent, and Content can be taught within the allotted time, all had $100 \%$ IRR. Whereas, only 4 had the same IRR value of $80 \%$. These themes include: Complete Module's content based on teaching strategies; Module difficulty appropriate to Secondary school; Activity promotes students' activeness in learning; and Lesson plan can be taught by suggested media.

Table 2. Percentage inter-rater reliability of subthemes on module's content

\begin{tabular}{|c|l|c|c|c|}
\hline Theme & \multicolumn{1}{|c|}{ Sub-Theme } & Agree & Disagree & IRR (\%) \\
\hline \multirow{3}{*}{$\begin{array}{l}\text { Module } \\
\text { content }\end{array}$} & Content complies with learning objectives & 5 & 0 & $100 \%$ \\
\cline { 2 - 5 } & Complete Module Content based on teaching strategies & 4 & 1 & $80 \%$ \\
\cline { 2 - 5 } & Content aligns with MOE chemistry curriculum & 5 & 0 & $100 \%$ \\
\cline { 2 - 5 } & module difficulty appropriate to Secondary school students & 4 & 1 & $80 \%$ \\
\cline { 2 - 6 } & Activity corresponds with content of module & 5 & 0 & $100 \%$ \\
\cline { 2 - 6 } & Activity promote students' activeness in learning. & 4 & 1 & $80 \%$ \\
\cline { 2 - 6 } & Arrangement of content is logical and coherent & 5 & 0 & $100 \%$ \\
\cline { 2 - 6 } & Content can be taught within allotted time & 5 & 0 & $100 \%$ \\
\cline { 2 - 6 } & Lesson plan can be taught by suggested media. & 4 & 1 & $80 \%$ \\
\hline
\end{tabular}

Since the context of this study is for Secondary school chemistry students within the Malaysia secondary education, it will be out of place to develop content that does not align with Malaysia's curriculum by MOE. The module's content considered the need by chemistry curriculum in Malaysia to involve students into active learning as contained in [42]. Much emphasis on the content is based on having a proper alignment with curriculum and learning objectives. Time learning components of the module to produce a suitable module for learning. teaching media comprised of the AR technology employed during the learning process and therefore, time to carry out this 
learning activity using the technology worth evaluating. All the evaluators responded that 80 Minutes is adequate to complete the learning activities. The module's difficulty is another factor that can render some challenges if not validated. Based on the experts' responses, secondary school students can easily understand the module. This is similar to some subthemes in the usability theme in Table 3 which stipulates that the module is comprise of terms that are easy to understand. Cognition of students varies based on their age and learning development [43] which inform why the module need to be appropriate with cognitive level of secondary school students [44]. On average, the content of the module is observed to suit teaching and learning of phase change to upper secondary school students.

\subsection{Usability}

The effectiveness of the module can be affected when there are usability challenges. As such, 5 subthemes in this theme were evaluated to determine how easy the module can be used for effective teaching and meaningful learning of phase change by Secondary school students. Experts' evaluation in Figure 3 shows that, 2 subthemes which include: Module can be used at homes and schools; and Easy to understand terms, all had $100 \%$ IRR. This is the maximum percentage of agreement that can be obtained which entails that all evaluators agreed to the subthemes and Secondary school students are very likely to easily understand the terms used in the module which may comprise scientific, non-scientific, and mathematical terms.

The other 3 subthemes: Maintained students' attention; AR is easy to use by Secondary school students [2], [30], and Module can be used by any party to teach students, had a less IRR value $(80 \%)$.

Table 3. Percentage inter-rater reliability of subthemes on module's usability

\begin{tabular}{|c|l|c|c|c|}
\hline Theme & \multicolumn{1}{|c|}{ Sub-Theme } & Agree & Disagree & IRR (\%) \\
\hline Usability & Maintained students' attention & 4 & 1 & $80 \%$ \\
\cline { 2 - 5 } & The AR is easy to use by Secondary school students & 4 & 1 & $80 \%$ \\
\cline { 2 - 5 } & Module can be used by any party to teach students & 4 & 1 & $80 \%$ \\
\cline { 2 - 5 } & Module can be used at homes, and schools & 5 & 0 & $100 \%$ \\
\cline { 2 - 5 } & Easy to understand terms & 5 & 0 & $100 \%$ \\
\hline
\end{tabular}

One of the comments from evaluators on the use of modules by any party to teach students is that, "unless a proper guidance is given". This is similar to the comment on students' use of AR technology. Since the AR interface in this study is new, students will require proper guidance to be able to effectively use it. More also, an expert failed to agree to the subtheme which stipulates that students' attention is maintained when they use AR. This is contrary to [35], who argue that some features are added to help detect students' location and working status on the AR systems which offer an opportunity to manage their attention. Furthermore, a meta-analysis shows that motivation and attention levels are increased when students learn with AR [3]. The agreement about this subtheme by most experts reveals that AR draws students' attention [2], [13], [30], 
which likely results from the interesting augmentation of what students only had to imagine during learning [30].

\subsection{Performances}

Similar to Usability, the Potential effectiveness of the Module can be affected by some factors categorized into this theme as subthemes. Based on experts' evaluation, Table 4 below shows that 6 subthemes had IRR values within the acceptable range $(>70 \%)$.

Table 4. Percentage inter-rater reliability of subthemes on module's performances

\begin{tabular}{|c|l|c|c|c|}
\hline \multicolumn{1}{|c|}{ Theme } & \multicolumn{1}{|c|}{ Sub-theme } & Agree & Disagree & IRR (\%) \\
\hline \multirow{5}{*}{ Performances } & Teaching strategy-student engagement & 4 & 1 & $80 \%$ \\
\cline { 2 - 5 } & Realization of learning objectives & 5 & 0 & $100 \%$ \\
\cline { 2 - 5 } & $\begin{array}{l}\text { linking sub microscopic, macroscopic and symbolic } \\
\text { representation through AR }\end{array}$ & 3 & 2 & $60 \%$ \\
\cline { 2 - 5 } & Visualization enhancement & 4 & 1 & $80 \%$ \\
\cline { 2 - 5 } & Activities helps nurture moral values & 2 & 3 & $40 \%$ \\
\cline { 2 - 5 } & $\begin{array}{l}\text { Materials used can be manipulated based on } \\
\text { suitability }\end{array}$ & 4 & 1 & $80 \%$ \\
\cline { 2 - 5 } & $\begin{array}{l}\text { appropriateness of topic sequence with students } \\
\text { developmental needs }\end{array}$ & 5 & 0 & $100 \%$ \\
\cline { 2 - 5 } & AR facilitates understanding of Phase change & 5 & 0 & $100 \%$ \\
\hline
\end{tabular}

Three of these themes: Realization of learning objectives; Appropriateness of topic sequence with students' developmental needs; and AR facilitates understanding of phase change all had $100 \%$ IRR while another 3: Teaching strategy-student engagement; Visualization enhancement; and Materials used can be manipulated, all had $80 \%$ IRR. In this theme, 2 subthemes; linking sub-microscopic, macroscopic, and symbolic representation (also known as multiple representations) [15] through AR; and activities that help nurture moral values were not agreed to by a significant number of evaluators which resulted in IRR values of $60 \%$ and $40 \%$ respectively. These values fall short of the acceptable limit of $>70 \%$. According to one of the expert evaluators that failed to agree to the former subtheme, the provision for symbolic representation within the AR system is needed to facilitate knowledge construction based on linking knowledge in the multiple representations. Furthermore, comments from 2 evaluators on the later subtheme questioned the association of this study (AR Module) with students' morals. Since the module is focused on enhancing the learning of scientific concepts, their feedback suggests that such consideration in the module can be revised.

\subsection{Assessment}

The last of the five main themes in this study is the Assessment which comprises only three subthemes. This describes the procedure of determining the extent of the intended learning outcome has been achieved. The result from the experts' evaluation shows 
that all the subthemes: Assessment align with the pedagogy; Assessment align with the cognitive level of Secondary school students [45]; and Assessment corresponds with module content, all had 100\% IRR. All the experts agreed to these subthemes. Each subtheme is based on the idea of constructive alignment which is expected to exist amongst learning objectives, content, and assessment parts of any instructional plan [11], [20].

Table 5. Percentage Inter-rater reliability of subthemes on assessment of learning in the module

\begin{tabular}{|c|l|c|c|c|}
\hline Theme & \multicolumn{1}{|c|}{ Sub-Theme } & Agree & Disagree & IRR (\%) \\
\hline Assessment & Assessment align with the pedagogy & 5 & 0 & $100 \%$ \\
\cline { 2 - 5 } & $\begin{array}{l}\text { Assessment align with cognitive level of Secondary } \\
\text { school students }\end{array}$ & 5 & 0 & $100 \%$ \\
\cline { 2 - 5 } & Assessment corresponds with module content & 5 & 0 & $100 \%$ \\
\hline
\end{tabular}

Since the learning objectives present what is intended to be achieved during the teaching and learning procedure, the assessment fits well with the objectives to provide information on the extent to which these objectives have been achieved. Reflecting on the evaluation of the module's objective and content, it can be observed that none of the subthemes fall out of the acceptable IRR value which therefore suggests that $100 \%$ IRR on Assessment indicates that both learning objectives, content, and assessment are constructively aligned.

\subsection{Summary of results}

From all the results presented for each theme, the summary is presented in Figure 3 which describes the amount in the percentage of the module based on the main themes that are reliable and considered to result in a very good module's potential effectiveness. Among the five themes analysed, $100 \%$ concerning each of the four themes: Objectives; Module Content; Usability; and Assessment were very good and reliable since none of their subthemes had an IRR below the acceptable limit $(>70 \%)$. Whereas, performances theme was the only to have $75 \%$ IRR considered good and reliable. This suggests that $25 \%$ of the performances may be revised.

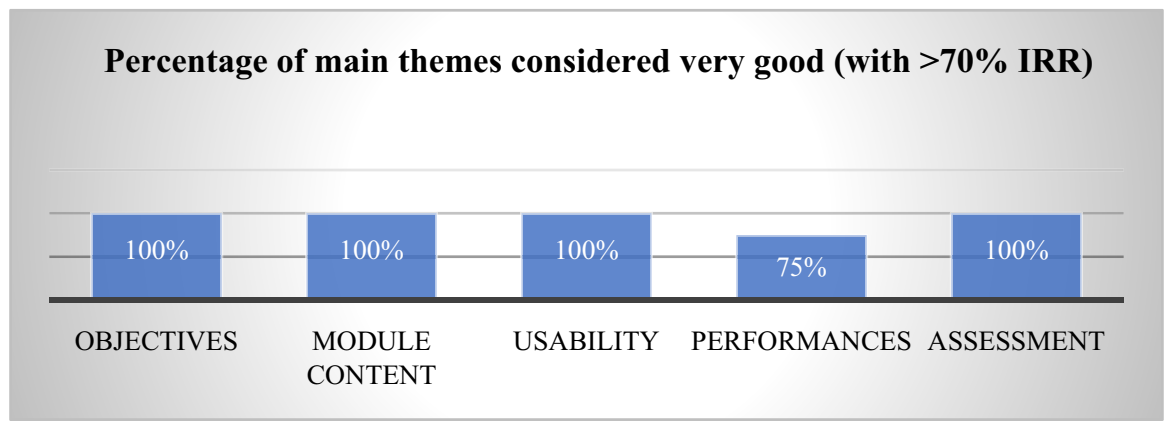

Fig. 3. Percentage of reliable main themes 
Despite the need for revision of $25 \%$ portion of performances, the overall evaluation by experts reveals that the AR Module has potential effectiveness with $100 \%$ IRR. The output of this result summary presents the five major aspects of the module that were validated to determine their percentage proportions that is good and can tell what category of the module is suitable or unsuitable for learning phase change. For instance, if the percentage of the module content that is reliable is short of $100 \%$, it then means that the module must be revised because what is expected of the students to learn is embodied in the content. Therefore, the module can be considered unsuitable for learning phase change.

Similarly, the usability is another factor that is crucial to development of modules or any other instructional material. The idea behind this module development envision that the instructional material should be developed to offer some appreciable degree of ease to the user [46] whereby the objectives of its provision will be achieved. For students to effectively visualize and make meaning of what they observe through use of $\mathrm{AR}$, it means that the module or the AR system must consist of some guiding mechanism either as word description or combination of words and different lights, colours or graphics, to ease possible difficulties that students might experience during the learning process. [2] and [30] highlights that students find AR very easy to use; and for which ever possible challenge that may arise, a proper guide is given in the module.

The performances in the AR module are the output that the module claims to elicit which appears that, the evaluators consider revising some component of the performances. For instance, claiming the module helps to nurture moral values was not considered relevant to the topic in which the module was developed. Such can be observed to have no effect on improving students learning of phase change. In the same vein, the module was considering improving students' ability to conceptualise phase change based on linking the sub-microscopic, macroscopic and symbolic representations which often pose some difficulties to chemistry students particularly when they can not visualize the sub microscopic substances. [15] highlighted the significance of learning conceptual knowledge in chemistry based on the multiple representation. It is on this basis that the AR module seek to facilitate not only the visualization of sub microscopic substances but also the learning through the multiple representation. The result from evaluators therefore, suggests for revising that provision in the module so that more of the symbolic representations can be added at each stages of the learning activity using the AR system. The Performances category largely determined potential effectiveness of the module since it constitute the expected output that the module is expected to yield. The last part which is the assessment had its all components valid and suitable to assess whether the pre-outlined instructional objectives have been achieved or not. All the basic expectation of students having to understand the distance of particles in solid and liquid states, the motion, the size, dispersion of the particles in liquid and solid states will be observed whether students meet up with these expectations or not.

\section{Importance of AR module}

AR module has tremendous importance to STEM teachers and students most especially for those into teaching and learning chemistry. AR module is designed to help 
chemistry teachers teach the concept of phase change effectively by engaging students in a learner-centred instructional approach to create a sense of ownership of what is expected of them to learn. The module has the potential to arouse as well as sustain students' interest in learning chemistry. Alternatively, since students are considered the central focus point in learning, AR module was developed to offer students a sense of active participation in learning phase change which is needed for them to construct their knowledge in STEM.

\section{Conclusion}

This study aimed at developing an augmented reality AR module for teaching and learning change of state of matter (phase change) by secondary school chemistry students. The study employed an ADDIE research and development instructional model and a qualitative research design was used in the study. The result of the evaluation shows that $100 \%$ of the module's objectives, content, (usability, and assessment indicators), and $75 \%$ of its performances were good and reliable which enable it to possess a very good potential effectiveness. it is hoped that AR module will become an important educational material that will not only make learning interesting but will promote meaningful learning of the concept of phase change.

\section{Recommendations}

Based on the suggestions from experts, similar augmented reality-based modules can be developed to present symbolic descriptions of the chemical particles at each stage of the phase change. This study was limited to phase change from liquid to solid using ice cream learning activity. Future studies can consider expanding to phase change for evaporation, and condensations using specified STEM project-based learning activities. More also, further studies can develop more Augmented reality-based modules for educating students on other topics of chemistry that present internal visualization complexity to students.

\section{Acknowledgement}

The authors would like to thank Universiti Teknologi Malaysia (UTM) for their support in making this project possible. This work was supported by the Research University Grant (Q.J130000.2453.09G35) initiated by UTM.

\section{References}

[1] Adadan, E., \& Ataman, M. M. (2020). Promoting senior primary school students' understanding of particulate nature of matter through inquiry instruction with multiple representations. Education 3-13, 3(13), 1-13. https://doi.org/10.1080/03004279.2020.1854960 
[2] Akçayır, M., \& Akçayır, G. (2017). Advantages and challenges associated with augmented reality for education: A systematic review of the literature. Educational Research Review, 20, 1-11. https://doi.org/10.1016/j.edurev.2016.11.002

[3] Arici, F., Yildirim, P., Caliklar, Ş., \& Yilmaz, R. M. (2019). Research trends in the use of augmented reality in science education: Content and bibliometric mapping analysis. Computers and Education, 142(August), 103647. https://doi.org/10.1016/j.compedu.2019.103647

[4] Astuti, T. N., Sugiyarto, K. H., \& Ikhsan, J. (2020). Effect of 3D visualization on students' critical thinking skills and scientific attitude in chemistry. International Journal of Instruction, 13(1), 151-164. https://doi.org/10.29333/iji.2020.13110a

[5] Badmus, O. T., \& Omosewo, E. O. (2020). Evolution of STEM, STEAM and STREAM Education in Africa: The Implication of the Knowledge Gap. International Journal on Research in STEM Education, 2(2), 99-106. https://doi.org/10.31098/ijrse.v2i2.227

[6] Bahrum, S., Wahid, N., \& Ibrahim, N. (2017). Integration of STEM Education in Malaysia and Why to STEAM. International Journal of Academic Research in Business and Social Sciences, 7(6), 645-654. https://doi.org/10.6007/IJARBSS/v7-i6/3027

[7] Branch R. M. (2009). Instructional design: The ADDIE approach (Vol. 722). Springer Science \& Business Media. https://doi.org/10.1007/978-0-387-09506-6

[8] Branch, R. M., \& Kopcha, T. J. (2014). Instructional Design Models. Handbook of Research on Educational Communications and Technology, 77-87. https://doi. org/10.1007/978-1-4614-3185-5

[9] Chee, K. N., Yahaya, N., \& Ibrahim, N. H. (2017). Effectiveness of mobile learning application in improving reading skills in Chinese language and towards post-attitudes. International Journal of Mobile Learning and Organization, 11(3), 210-225. https://doi.org/10.1504/ IJMLO.2017.085347

[10] Chong, C. J. (2019). Preliminary review on preparations in Malaysia to improve stem education. Journal of Sustainability Science and Management, 14(5), 135-147.

[11] Díaz, M. T. V., \& González, M. G. (2016). Constructively aligned assessment: An integral approach to translation teaching and learning. Meta LXI, 61(2), 276-298. https://doi. org/10.7202/1037760ar

[12] Fahmina, S. S., Indriyanti, N. Y., Setyowati, W. A. E., Masykuri, M., \& Yamtinah, S. (2019). Dimension of Chemical Literacy and its Influence in Chemistry Learning. Journal of Physics: Conference Series, 1233(1). https://doi.org/10.1088/1742-6596/1233/1/012026

[13] Garzón, J., Pavón, J., \& Baldiris, S. (2019). Systematic review and meta-analysis of augmented reality in educational settings. Virtual Reality, 23(4), 447-459. https://doi. org/10.1007/s10055-019-00379-9

[14] Hoyt, W. T. (2019). Interrater Reliability and Agreement. The Reviewer's Guide to Quantitative Methods in the Social Sciences, 132-144. https://doi.org/10.4324/9781315755649-10

[15] Johnstone, A. H. (2009). Multiple Representations in Chemical Education. In International Journal of Science Education(Vol.31, Issue 16). https://doi.org/10.1080/09500690903211393

[16] Kelley, T. R., \& Knowles, J. G. (2016). A conceptual framework for integrated STEM education. International Journal of STEM Education, 3(1). https://doi.org/10.1186/ $\underline{\mathrm{s} 40594-016-0046-\mathrm{Z}}$

[17] Kiger, M. E., \& Varpio, L. (2020). Thematic analysis of qualitative data: AMEE Guide No. 131. Medical Teacher, 42(8), 846-854. https://doi.org/10.1080/0142159X.2020.1755030

[18] Lestari, T. P., \& Sumarti, S. S. (2018). STEM-Based Project Based Learning Model to Increase Science Process and Creative Thinking Skills of 5th Grade. Journal of Primary Education, 7(1), 18-24.

[19] Luckin, R., \& Fraser, D. S. (2011). Limitless or pointless ? An evaluation of augmented reality technology in the school and home. International Journal of Enhanced Learning, 3(5), 510-524. https://doi.org/10.1504/IJTEL.2011.042102 
[20] Mahanan, M. S., Talib, C. A., \& Ibrahim, N. H. (2021). Online Formative Assessment in Higher STEM Education; A Systematic Literature Review. Asian Journal of Assessment in Teaching and Learning, 11(1), 47-62.

[21] Meisner, J., Donnelly, W., \& Masnier, R. R. (2007). Augmented Reality Technology. United States Patent, 2(12).

[22] Nersesian, E., Spryszynski, A., \& Lee, M. J. (2019). Integration of Virtual Reality in Secondary STEM Education. 2019 9th IEEE Integrated STEM Education Conference, ISEC 2019, 83-90. https://doi.org/10.1109/ISECon.2019.8882070

[23] Nuić, I., \& Glažar, S. A. (2020). The effect of e-learning strategy at primary school level on understanding structure and states of matter. Eurasia Journal of Mathematics, Science and Technology Education, 16(2). https://doi.org/10.29333/ejmste/114483

[24] Olakanmi, E. E. (2017). The Effects of a Flipped Classroom Model of Instruction on Students' Performance and Attitudes Towards Chemistry. Journal of Science Education and Technology, 26(1), 127-137. https://doi.org/10.1007/s10956-016-9657-x

[25] Özmen, H., \& Kenan, O. (2007). Determination of the Turkish primary students ' views about the particulate nature of matter. Asia-Pacific Forum on Science Learning and Teaching, 8(1), 1-15.

[26] Peterson, C. (2003). Bringing ADDIE to Life: Instructional Design at Its Best - Learning \& Technology Library (LearnTechLib). Journal of Educational Multimedia and Hypermedia, 12, 227-241. http://www.learntechlib.org/p/2074/

[27] Ramli, A. A., \& Ibrahim, N. H. (2018). Q-STEM Module Promotes Al-Quran Appreciation in Teaching STEM. Proceedings - 2017 7th World Engineering Education Forum, WEEF 2017- In Conjunction with: 7th Regional Conference on Engineering Education and Research in Higher Education 2017, RCEE and RHEd 2017, 1st International STEAM Education Conference, STEAMEC 201, July, 623-627. https://doi.org/10.1109/ WEEF.2017.8466968

[28] Ramli, A. A., Ibrahim, N. H., Surif, J., Abd, M., \& Bunyamin, H. (2017). Teachers ' readiness in teaching stem education. Man In India, 97 (13)(13), 343-350.

[29] Robert, M. C., \& Scott, W. S. (2013). Stem project-based learning (M. C. Robert, M. M. Capraro, \& R. M. James (eds.)). SENSE PUBLISHERS ROTTERDAM/BOSTON/TAIPEI.

[30] Sirakaya, M., \& Cakmak, E. K. (2018). The effect of augmented reality use on achievement, misconception and course engagement. Contemporary Educational Technology, 9(3), 297-314. https://doi.org/10.30935/cet.444119

[31] Slapnicar, M., Devetak, I., Glazar, S. A., \& Pavlin, J. (2015). Identification of the Understanding of the States of Matter of Water and Air Among Slovenian Students Aged 12, 14 and 16 Years Through Solving. Journal of Baltic Science Education, 16(3), 308-323. https:// doi.org/10.33225/jbse/17.16.308

[32] Taber, K. S. (2013). Revisiting the chemistry triplet: Drawing upon the nature of chemical knowledge and the psychology of learning to inform chemistry education. Chemistry Education Research and Practice, 14(2), 156-168. https://doi.org/10.1039/C3RP00012E

[33] Tsai, C. C. (1999). Overcoming junior high school students misconceptions about microscopic views of phase change: A study of an analogy activity. Journal of Science Education and Technology, 8(1), 83-91. https://doi.org/10.1023/A:1009485722628

[34] Uchegebu, R., Oguoma, C., Elenwoke, U., \& Ogbuagu, O. (2016). Perception of Difficult Topics in Chemistry Curriculum by Senior Secondary School (II) Students in Imo State. AASCIT Journal of Education, 2(3), 19-23. http://article.aascit.org/file/pdf/ 9730743.pdf

[35] Wu, H. K., Lee, S. W. Y., Chang, H. Y., \& Liang, J. C. (2013). Current status, opportunities and challenges of augmented reality in education. Computers and Education, 62, 41-49. https://doi.org/10.1016/j.compedu.2012.10.024 
[36] Harta, J., Listyarini, R., Pemenang, F., Wijayanti, L., \& Lee, W. (2020). Developing Small Scale Chemistry Practicum Module to Identify Students' Ability in Predict-Observe-Explain (POE) Implementation. JKPK (Jurnal Kimia Dan Pendidikan Kimia), 5(1), 91-99. https:// doi.org/10.20961/jkpk.v5i1.38537

[37] Pamenang, F. D. N., Harta, J., Listyarini, R. V., Wijayanti, L. W., Ratri, M. C., Hapsari, N. D., Asy'Ari, M., \& Lee, W. (2020). Developing chemical equilibrium practicum module based on guided inquiry to explore students' abilities in designing experiments. Journal of Physics: Conference Series, 1470(1), 1-7. https://doi.org/10.1088/1742-6596/1470/1/012097

[38] Puspasari, P., Astuti, I., \& Suratman, D. (2018). The Development of Problem-Based Practicum Module to Learn Reaction Rate and Basa-Acid Solution. JETL (Journal of Education, Teaching and Learning), 3(2), 206. https://doi.org/10.26737/jetl.v3i2.748

[39] Gamson, D. A., Eckert, S. A., \& Anderson, J. (2019). Standards, instructional objectives and curriculum design: A complex relationship. Phi Delta Kappan, 100(6), 8-12. https://doi. org/10.1177/0031721719834022

[40] Kamat, V. V, Pathak, C., Bawa, M. S., Dash, N. K., \& Kumar, S. (2018). Unit-6 Instructional Objectives. IGNOU.

[41] Mager, R. F. (1962). Preparing instructional objectives.

[42] MOE. (2006). Integrated Curriculum for Secondary Schools Curriculum: Curriculum Specifications Chemistry Form 5-Education-Ministry of Education Malaysia.

[43] Gill, D., \& Prowse, V. (2015). Cognitive ability, character skills, and learning to play. Forthcoming in Journal of Political Economy. https://doi.org/10.2139/ssrn.2448144

[44] Bjorklund, D. F., \& Causey, K. B. (2017). Children's thinking: Cognitive development and individual differences. Sage Publications.

[45] Fuad, A., \& Rahim, A. (2020). Guidelines for Online Assessment in Emergency Remote Teaching during the COVID-19 Pandemic. Education in Medicine Journal, 12(2), 59-68. https://doi.org/10.21315/eimj2020.12.2.6

[46] Jordan, P. W. (2020). An introduction to usability. CRC Press. https://doi.org/10.1201/ $\underline{9781003062769}$

\section{Authors}

Mangai Solomon Mahanan is a final semester Student pursuing Master's degree in Chemistry Education Universiti Teknologi Malaysia (UTM). He has excellent grades in both core and non-core courses. He was also the director of $13^{\text {th }}$ School of Education Innovation day committee 2021, at the same Universiti. Mangai is the present General Secretary of International Students Society of Nigeria at UTM and is a certified Chemistry teacher with Teacher's Registration Council of Nigeria having had 3-year teaching experience in senior secondary school chemistry. (Email: solomonmangai2018@,gmail. com and mangai@graduate.utm.my).

Nor Hasniza Ibrahim is a senior lecturer in Department of Educ Science, Mathematics and Multimedia Creative, Faculty of Science Social and Humanities, Universiti Teknologi Malaysia, Johor Bahru, Malaysia, 81310. She received her Bachelor in Biomedical Sciences from Universiti Putra Malaysia, Master's Degree and Doctor of Philosophy in Chemistry Education from Universiti Teknologi Malaysia. Her research interest is regarding science education, chemistry education and STEM education. She now works as senior lecturer in She also currently actively involved in research and programs related to STEM education and indigenous people (Email: p-norhaniza@utm.my). 
Johari Surif is associate professor in Department of Educ Science, Mathematics and Multimedia Creative, Faculty of Science Social and Humanities, Universiti Teknologi Malaysia, Johor Bahru, Malaysia, 81310. He received Bachelor in Environmental Sciences from Universiti Kebangsaan Malaysia, Master's Degree and Doctor of Philosophy in Chemistry Education from Universiti Teknologi Malaysia. His research interest is regarding science education, chemistry education and STEM education. He also currently actively involved in research and programs related to STEM education, community and many more (Email: johari surif@utm.my).

Chee Ken Nee received the Ph.D. degree in Educational Technology, Universiti Teknologi Malaysia, Malaysia, in 2018. He is Professional Technologist registered under Malaysian Board of Technologist (MBOT). He is also senior member of IEEE (SMIEEE). A Global Teacher Award 2020 receiver. Top 30 Microsoft Innovative Educator Expert 2020. He is currently a Senior Lecturer with Universiti Pendidikan Sultan Idris, Malaysia. His primary research interests include mobile learning, augmented reality, virtual reality, robotics in education, internet of things, artificial intelligence and computer-based learning. He is a reviewer for many ISI and Scopus indexed journals. $\mathrm{He}$ is also a jury for many prestigious innovation competitions in international and national level. He even has presented in various international stage as speaker including the USA. Innovation in teaching and learning also become his interest recently especially in this pandemic era. His research H-index is 4 with 220 citations. Work more than 12 years in education industry as school teacher and half year as assistant director in Educational Technology and Resource Division, Ministry of Education Malaysia. (Email: cheekennee@,fskik.upsi.edu.my).

Article submitted 2021-09-06. Resubmitted 2021-10-05. Final acceptance 2021-10-07. Final version published as submitted by the authors. 